\title{
Outcomes of four patients with homocysteine remethylation disorders detected by newborn screening
}

\author{
Derek Wong, MD1, Silvia Tortorelli, MD, PhD², Lisa Bishop, MD³, Elizabeth A. Sellars, MD, \\ Lisa A. Schimmenti, MD ${ }^{5-7}$, Natalie Gallant, MD1, Carlos E. Prada, MD, Robert J. Hopkin, MD, \\ Nancy D. Leslie, MD ${ }^{8}$, Susan A. Berry, MD ${ }^{5-7}$, David S. Rosenblatt, MD ${ }^{9}$, Amy L. Fair, MD ${ }^{10}$, \\ Dietrich Matern, MD, PhD², Kimiyo Raymond, $\mathrm{MD}^{2}$, Devin Oglesbee, $\mathrm{PhD}^{2}$, Piero Rinaldo, MD, $\mathrm{PhD}^{2}$ \\ and Dimitar Gavrilov, MD, PhD²
}

Purpose: We evaluated the clinical outcome in homocysteine remethylation disorders following newborn screening (NBS) and initiation of early specific treatment.

Methods: Five patients with remethylation disorders were included in this study.

Results: Two asymptomatic patients (one with $c b l G$ and one with $c b l E$ ) were identified by NBS using an approach that combines a postanalytical interpretive tool (available on the Region 4 Stork (R4S) collaborative project website, http://www.clir-r4s.org) and a second-tier test for total homocysteine determination. Both the initial screening and the second-tier test are performed on the same blood spot, with no additional patient contact, resulting in no false-positive outcomes. Two additional patients with methylenetetrahydrofolate reductase deficiency were detected by NBS using low methionine as a marker.

\section{INTRODUCTION}

Remethylation disorders result from defective remethylation of homocysteine (Hcy) to methionine (Met) because of deficient enzymes responsible for three biochemical reactions. Briefly, Hcy is methylated to Met by the action of 5-methyltetrahydrofolate-homocysteine S-methyltransferase (methionine synthase, EC 2.1.1.13) requiring methylcobalamin as a cofactor and utilizing 5-methyltrahydrofolate supplied through the action of $(N) 5,10$-methylenetetrahydrofolate reductase (MTHFR, EC 1.5.1.20) as a methyl group donor. Reactivation of methionine synthase is provided by a reduction reaction catalyzed by methionine synthase reductase (EC 2.1.1.135). Deficiency of methionine synthase results in homocystinuria-megaloblastic anemia ( $c b l G$ complementation type, MIM 250940); MTHFR is associated with MTHFR deficiency (MIM 236250) and methionine synthase reductase
Although already symptomatic despite the early diagnosis, the latter two patients greatly improved with treatment and their outcomes are compared with that of another patient with methylenetetrahydrofolate reductase deficiency and significant morbidity who was diagnosed clinically at 3 months of age.

Conclusion: Early detection by NBS and timely and specific treatment considerably improve at least short-term outcomes of homocysteine remethylation disorders. When a remethylation disorder is suspected, group-specific treatment could be started prior to the completion of in vitro confirmatory testing because all disorders from this group require similar intervention.

Genet Med advance online publication 9 April 2015

Key Words: homocysteine; newborn screening; Region 4 Stork tool; Remethylation disorders; second-tier testing

is associated with homocystinuria-megaloblastic anemia ( $c b l E$ complementation type, MIM 236270). Patients with inborn errors of remethylation enzymes present with a variety of symptoms, including poor feeding, hypotonia, seizures, coma, and death. Demyelination/brain abnormalities and hematologic abnormalities are frequent. ${ }^{1,2}$ The biochemical hallmark of these disorders is low/low normal Met, high Hcy, and the absence of elevated methylmalonic acid levels. ${ }^{1}$ Because homocystinuria, $c b l D$ type, variant 1 , has similar biochemical characteristics, it is included in this group, which is referred to here as "remethylation disorders" henceforth. Early diagnosis and treatment of at least severe MTHFR deficiency lead to either reduction or even prevention of symptoms if initiated at the earliest possible time in the first month of life before irreversible central nervous system central nervous system (CNS) damage occurs. ${ }^{2-4}$ Recently, an approach utilizing low

\footnotetext{
${ }^{1}$ Department of Pediatrics, Division of Medical Genetics, David Geffen School of Medicine at UCLA, Los Angeles, California, USA; ${ }^{2}$ Biochemical Genetics Laboratory, Mayo Clinic College of Medicine, Rochester, Minnesota, USA; ${ }^{3}$ National Human Genome Research Institute, National Institutes of Health, Bethesda, Maryland, USA; ${ }^{4}$ Department of Pediatrics, Section of Genetics and Metabolism, University of Arkansas for Medical Sciences, Little Rock, Arkansas, USA; ${ }^{5}$ Department of Pediatrics, Division of Genetics and Metabolism, Institute of Human Genetics, University of Minnesota, Minneapolis, Minnesota, USA; ${ }^{6}$ Department of Ophthalmology, Division of Genetics and Metabolism, Institute of Human Genetics, University of Minnesota, Minneapolis, Minnesota, USA; ${ }^{7}$ Department of Genetics, Cell Biology and Development, Division of Genetics and Metabolism, Institute of Human Genetics, University of Minnesota, Minneapolis, Minnesota, USA; ${ }^{8}$ Division of Human Genetics, Cincinnati Children's Hospital Medical Center, Cincinnati, Ohio, USA; ${ }^{9}$ Department of Human Genetics, McGill University and the Research Institute of the McGill University Health Center, Montreal, Quebec, Canada; ${ }^{10}$ Fairview Elk River Clinic, Elk River, Minnesota, USA. Correspondence: Dimitar Gavrilov (Gavrilov.dimitar@mayo.edu)
} 
Met cutoff followed by tHcy determination in the same dried blood spot was developed. ${ }^{5}$

We report four cases of remethylation disorders identified soon after birth and compare their clinical outcomes with an additional patient with MTHFR deficiency diagnosed clinically at 3 months of age.

\section{Case 1: cb/G}

\section{MATERIALS AND METHODS}

A full-term male was born to a primigravida mother. Both parents were healthy. The family history was unremarkable for metabolic disorders or unknown childhood neurologic disease or death. During the pregnancy, ultrasound detected small kidneys at 20 weeks and an abnormal heart rate at 32 weeks; both findings resolved spontaneously.

The initial newborn screen revealed low Met with an abnormal ratio of Met to phenylalanine (Met/Phe) (Table 1). These abnormalities necessitated a second-tier test, which revealed an elevated total Hcy (tHcy).,5 Follow-up plasma testing on day 9 of life showed significantly elevated tHcy and normal Met. At 4 months of age, his parents gave consent to a skin biopsy for complementation studies of fibroblasts, the results of which were consistent with functional methionine synthase (MTR) deficiency. ${ }^{7,8}$ The diagnosis was verified by the identification of two alterations in MTR encoding methionine synthase: a known mutation c.3518C $>\mathrm{T}$ (p.P1173L) $)^{9}$ and a novel variant c.3109G $>$ C (p.A1037P), which has not been described previously. The amino acid residue at position 1037 resides in one of the $\beta$-strands located in the activation domain of MTR protein. ${ }^{10}$ It is highly conserved (up to Caenorhabditis elegans species), and in silico analysis using the Mutation Tester2 algorithm ${ }^{11}$ predicts it to be pathogenic (summarized in Table 2).

At the time of his initial evaluation on day 14, he weighed 4,160 g. A repeat tHcy test on that day yielded $136 \mu \mathrm{mol} / \mathrm{l}$. Blood smear morphology was unremarkable for age. Formal neurologic assessment was normal, as was magnetic resonance imaging of his brain. He began treatment with oral betaine $(100 \mathrm{mg} / \mathrm{kg} /$ day), pyridoxine $12.5 \mathrm{mg}$ daily, riboflavin $6.25 \mathrm{mg}$ daily, folate $2 \mathrm{mg}$ daily, carnitine $70 \mathrm{mg}$ three times per day, and aspirin $12 \mathrm{mg}$ daily. He was also treated with hydroxycobalamin $1 \mathrm{mg}$ subcutaneous injection every other day. Two weeks after initiation treatment, his tHcy level decreased to $40 \mu \mathrm{mol} / \mathrm{l}$ and his Met level increased to $60 \mu \mathrm{mol} / \mathrm{l}$. His betaine dosage was increased to and maintained at $200 \mathrm{mg} / \mathrm{kg} /$ day. The follow-up tHcy and Met levels are summarized in Table 1.

Over a nearly 3-year follow-up period, this child has met all motor milestones. His language development is mildly delayed, but he speaks in sentences. Head circumference measured at age of 5 years and 6 months was $53.3 \mathrm{~cm}$ (84th percentile). His hearing was recently evaluated and is normal. He had some mild limb shaking that was not felt to be seizure activity and that resolved spontaneously. He is socially engaging and participates in age-appropriate physical activities.

\section{Case 2: cblE}

A full-term male was the second child born to his mother. No abnormalities or complications were reported during the pregnancy. Both parents were healthy but had cognitive difficulties requiring special education services. The family history was unremarkable for metabolic disorders or unknown childhood

Table 1 Newborn screening results, confirmatory testing, and follow-up results

\begin{tabular}{|c|c|c|c|c|c|c|c|c|c|c|c|c|c|c|c|}
\hline \multirow[b]{3}{*}{ Case } & \multirow[b]{3}{*}{ Diagnosis } & \multirow{3}{*}{$\begin{array}{c}\text { Age at } \\
\text { diagnosis }\end{array}$} & \multirow{2}{*}{\multicolumn{2}{|c|}{$\begin{array}{l}\text { Newborn } \\
\text { screening }\end{array}$}} & \multirow{3}{*}{$\begin{array}{c}\begin{array}{c}\text { Second } \\
\text { tier }\end{array} \\
\text { Hcy }\end{array}$} & \multicolumn{10}{|c|}{ Plasma amino acids } \\
\hline & & & & & & \multicolumn{2}{|c|}{ Initial } & \multicolumn{2}{|c|}{ 1-3 months } & \multicolumn{2}{|c|}{ 3-6 months } & \multicolumn{2}{|c|}{1 year } & \multicolumn{2}{|c|}{3 years } \\
\hline & & & Met & Met/Phe & & Met & Hcy & Met & Hcy & Met & Hcy & Met & Hcy & Met & Hcy \\
\hline 1 & $c b / G$ & 14 days & 9.7 & 0.14 & 45 & 20 & 106 & 60 & 30 & 30 & 30 & 30 & 38 & 30 & 35 \\
\hline 2 & $c b / E$ & 8 days & 9.8 & 0.17 & 121 & 10 & 183 & n.a. & n.a. & n.a. & n.a. & 15 & 70 & 45 & 70 \\
\hline 3 & MTHFR & 16 days & 8.0 & 0.12 & 26 & $<2$ & 243 & 87 & 106 & 42 & 114 & 10 & 87 & 14 & 96 \\
\hline 4 & MTHFR & 11 days & 5.6 & 0.10 & n.d. & 4 & 215 & 29 & 91 & 273 & 85 & 58 & 45 & 20 & 81 \\
\hline 5 & MTHFR & $>90$ days & $10.3^{a}$ & $0.17^{a}$ & n.d. & 0 & 148 & $<8$ & $10^{c}$ & 22 & 96 & 10 & $12^{c}$ & 16 & $5^{c}$ \\
\hline $\begin{array}{l}\text { Reference } \\
\text { range }\end{array}$ & & & $11-39$ & $0.23-0.75^{b}$ & $4-11^{b}$ & $11-35$ & $<13$ & $11-35$ & $<13$ & $11-35$ & $<13$ & $11-35$ & $<13$ & $11-37$ & $<13$ \\
\hline
\end{tabular}

All values reflect tHcy concentration.

Met, methionine; n.a., not available; n.d., not determined; Phe, phenylalanine; Hcy, homocysteine; tHcy, total Hcy.

aData retrieved retrospectively; newborn screening reported as negative. ${ }^{b}$ From R4S (http://www. clir-r4s. org). ${ }^{C}$ Free homocysteine.

Table 2 Molecular characterization of five patients with remethylation disorders

\begin{tabular}{|c|c|c|c|}
\hline Case (gene) & Mutation(s) ${ }^{a}$ & Predicted effect & Comments \\
\hline $1(\mathrm{MTR})$ & c. $3518 C>T / C .3109 G>C$ & p.P1173L/p.A1037P & Gulati et al., $9 /$ novel missense mutation \\
\hline 2 (MTRR) & c. $340 \mathrm{C}>\mathrm{T} / \mathrm{c} .358 \mathrm{G}>\mathrm{A}$ & p.R114X/p.A120T & Wilson et al., ${ }^{13} /$ novel missense mutation \\
\hline 3 (MTHFR) & c.662delG/c.662delG & p.G221Efs*20/p.G221Efs*20/ & Novel deletion leading to premature stop codon \\
\hline 4 (MTHFR) & c. $236+1 \mathrm{G}>\mathrm{A} / \mathrm{c} .236+1 \mathrm{G}>\mathrm{Av}$ & - & Novel splice site mutation \\
\hline 5 (MTHFR) & c.152G>C/1541_1542del & p.R51P/p.E514Vfs*23 & Goyette et al., ${ }^{14} /$ Sibani et al. ${ }^{15}$ \\
\hline
\end{tabular}

MTHFR, gene encoding (N)5,10-methylenetetrahydrofolate reductase; MTR, gene encoding methionine synthase; MTRR, gene encoding methionine synthase reductase.

aAll alterations are reported according to human reference genome build hg19 (UCSC Feb 2009)/Genome Reference Consortium GRCh37. 
neurologic disease or death. Initial newborn screening (NBS) revealed a low Met and abnormal Met/Phe ratio and second-tier testing showed an elevated tHcy; both findings were confirmed in plasma (Table 1). At 2.5 months of age, a skin biopsy was performed for complementation analysis, revealing an underlying deficiency of methionine synthase reductase (MTRR) and placing this patient in the $c b l E$ complementation group. ${ }^{12}$ The diagnosis was confirmed by the identification of two alterations in MTRR encoding methionine synthase reductase: a known mutation c.340C $>\mathrm{T}$ (p.R114X) ${ }^{13}$ and a novel variant c.358G $>\mathrm{A}$ (p.A120T), which has not been described previously. The amino acid residue at amino acid position 120 is highly conserved (up to C. elegans species), and in silico analysis using Mutation Taster2 algorithm ${ }^{11}$ predicts it to be pathogenic (summarized in Table 2). The parents are carriers for the above-mentioned variants.

At the time of his initial evaluation on day 8 of life, he weighed $3,220 \mathrm{~g}$ and was feeding well. No neurologic abnormalities were noted and an MRI performed later at 1 month of age was unremarkable. Megaloblastic anemia became apparent at 4 years of age; prior to that point, the patient had normal mean corpuscular volume. Treatment with oral betaine $200 \mathrm{mg} /$ $\mathrm{kg} /$ day, folic acid $1 \mathrm{mg}$ daily, pyridoxine $12.5 \mathrm{mg}$ daily, aspirin $12 \mathrm{mg}$ daily, and riboflavin $6.25 \mathrm{mg}$ daily was initiated. He was also treated with hydroxycobalamin $1 \mathrm{mg}$ subcutaneously daily. Two weeks after initiation of therapy, his tHcy level decreased to $120.9 \mu \mathrm{mol} / \mathrm{l}$ and his Met increased to $40 \mu \mathrm{mol} / \mathrm{l}$. His betaine dosage is adjusted periodically for weight. His Hcy levels range from 50 to $150 \mu \mathrm{mol} / \mathrm{l}$. The follow-up tHcy and Met levels are summarized in Table 1.

At 17 months of age he had met all appropriate motor milestones but has had some mild motor delays, particularly in reaching for objects, and mild hypertonia. He had some slight shaking spells but two electroencephalograms were normal. He held his right hand to his side with his fist closed between ages 1 and 3, but if presented with an object he would use his hand. This finding was resolved at age 4 . His head circumference at age of 4 years and 6 months was $50 \mathrm{~cm}$ (33rd percentile).

\section{Case 3: MTHFR}

A full-term male was born to a gravida 4 para 5 mother. Both parents were healthy. The family history was unremarkable for metabolic disorders or unknown childhood neurologic disease or death. The results of his NBS, second-tier test, and confirmatory testing are summarized in Table 1 . Molecular analysis of MTHFR showed a homozygous single nucleotide deletion in Exon 5, c.662delG (p.G221Efs ${ }^{\star} 20$ ). This variant has not been reported previously; however, because it leads to frameshift and premature stop 20 codons downstream, it is highly likely to be deleterious (summarized in Table 2).

In the first week of life the patient was feeding adequately but had a weak cry and abnormal breathing after $48 \mathrm{~h}$. At the time of initial evaluation at age 16 days, the patient was found to be dehydrated with abnormal respirations, neutropenia (absolute

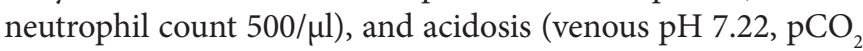

74). Hemoglobin was $14.8 \mathrm{~g} / \mathrm{dl}$, with a mean corpuscular volume of $100.2 \mathrm{fl}$ (normal for age). He was intubated and treated for presumed sepsis. Daily treatment began with betaine $3 \mathrm{~g}$, hydroxycobalamin $1 \mathrm{mg}$ intramuscularly, vitamin $\mathrm{B}_{6} 100 \mathrm{mg}$, leucovorin $10 \mathrm{mg}$, and levocarnitine $55 \mathrm{mg}$ three times per day. Oral supplementation with Met $(150 \mathrm{mg})$ was initiated 6 days after admission.

Six days after initiation of treatment, plasma tHcy decreased to $111 \mu \mathrm{mol} / \mathrm{l}$. One week after starting oral supplementation with Met, plasma Met level increased to $87 \mu \mathrm{mol} / \mathrm{l}$. Cerebrospinal fluid (CSF) analysis showed a 5-methylenetetrahydrofolate level $<5 \mathrm{nmol} / \mathrm{l}(40-120 \mathrm{nmol} / \mathrm{l})$ with normal neurotransmitter levels. The patient was extubated 6 days after admission, and feedings increased until discharge home 28 days after admission. After the diagnosis of MTHFR deficiency was established, hydroxycobalamin injections were discontinued and Deplin (5-methyltetrahydrofolate) was substituted for leucovorin. The follow-up tHcy and Met levels are summarized in Table 1.

At age 6 months the patient was feeding and growing well, was developing appropriately, and had a normal neurologic examination. However, by 1 year of age he had some developmental delay, and at 34 months of age he was only speaking four words, had mild hypotonia, and required physical and occupational therapy. Of note, social factors have prevented this patient from having all prescribed medications administered regularly. His head circumference at age of 39 months was $46 \mathrm{~cm}$ ( $<3 \mathrm{rd}$ percentile).

\section{Case 4: MTHFR}

A full-term female was born to a gravida 2 para 2 mother. The family history was unremarkable for metabolic disorders or unknown childhood neurologic disease or death; however, there was distant consanguinity. The outcome of the investigations that led to a biochemical diagnosis of a remethylation disorder is shown in Table 1. In addition, 5MTHF was undetectable in CSF and there was no evidence of macrocytosis. Molecular analysis of MTHFR showed a homozygous splice site mutation $(c .236+1 \mathrm{G}>\mathrm{A})$. This variant has not been described previously (summarized in Table 2).

The patient was admitted to a community hospital at day 9 of life for indirect hyperbilirubinemia. She had some apnea, with 2-6 s between breaths. Although she was described as having cyanosis and lethargy, when she was transferred to the University of California Los Angeles Medical Center she was stable and did not require intubation. Mild hypotonia was noted. Treatment was started with betaine $2 \mathrm{~g}$ per day, Met $140 \mathrm{mg}$ per day, 5-methyltetrahydrofolate $7.5 \mathrm{mg}$ per day, pyridoxine $100 \mathrm{mg}$ per day, and hydroxycobalamin $1 \mathrm{mg}$ per day. Hydroxycobalamin was stopped after it was determined that the patient did not have a cobalamin defect.

The patient had some feeding difficulties and emesis and required gavage feeding until 3 weeks after admission. Ophthalmologic examination revealed retinal hemorrhages of unclear etiology. She was transferred back to the admitting hospital, where she was placed on full oral feeds. Her hypotonia 
resolved. Follow-up laboratory tests 7 weeks after admission revealed a lowered plasma tHcy level $(91 \mu \mathrm{mol} / \mathrm{l})$ and a normal Met level $(29 \mu \mathrm{mol} / \mathrm{l})$. At 4 months of age, the patient was smiling, had normal interactions, and had started rolling over. The follow-up tHcy and Met levels are summarized in Table 1. Her head circumference at age of 1 year was $44 \mathrm{~cm}$ (10th percentile).

By 21 months of age, she had normal physical development but only said one word and was undergoing evaluation for speech therapy. She has normal muscle tone and her physical examination has been normal.

\section{Case 5: MTHFR}

A full-term female was born to a primigravida mother. Both parents were healthy. Pregnancy was uncomplicated. The family history was unremarkable for metabolic disorders or unknown childhood neurologic disease or death. At that time, the newborn screen was reported as normal (the performing laboratory did not apply a low cutoff for Met and the Met/Phe ratio). Retrospective analysis of the residual NBS sample showed elevated tHcy (Table 1). Sequence analysis of MTHFR revealed compound heterozygosity for the known pathogenic mutations c.152G $>$ C (p.R51P) ${ }^{14}$ and c.1541_1542del (p.E514Vfs $\left.{ }^{\star} 23\right)^{15}$ (summarized in Table 2).

The mother reported that the infant had abnormal breathing from birth and constant congestion. The pediatrician noted arrested head growth at 1 month of age $(36 \mathrm{~cm})$ and overriding sutures. The initial genetics evaluation was performed at 3 months of age during admission for supraglottoplasty, from which the patient had a slow recovery. Profound developmental delay, impaired overall growth with microcephaly, and apnea were observed. Brain MRI performed at the same time revealed an underdeveloped sulcation pattern and hypomyelination with small brain volume. Plasma amino acids showed elevated free Hcy $(22 \mu \mathrm{mol} / \mathrm{l}$, reference range $<2)$ and undetectable Met. Total Hcy at this time was $148 \mu \mathrm{mol} / \mathrm{l}$. Hemoglobin was $13.4 \mathrm{~g} / \mathrm{dl}$, with a mean corpuscular volume of $95.3 \mathrm{fl}$ (both normal for age).

Once laboratory evaluation indicated a likely diagnosis of MTHFR deficiency, the patient was started on betaine $(100 \mathrm{mg} /$ $\mathrm{kg} /$ day) and folic acid ( $0.4 \mathrm{mg} /$ day). Six weeks after starting these medications, the patient showed marked improvement. Free Hcy was undetectable and Met was $22 \mu \mathrm{mol} / \mathrm{l}$ (normal: 11-33). Her gross motor skills went from those of a newborn to those of a 3-month-old at the chronologic age of 6 months. In addition, her head circumference grew $2 \mathrm{~cm}$ in 2 months. The follow-up tHcy and Met levels are summarized in Table 1.

At 4 years and 9 months, she remained microcephalic ( -6 SD) but was walking independently. She has been weaned from G-tube feedings but has remained non-verbal.

\section{Enhanced postanalytical interpretation of newborn screening results}

As reported recently, ${ }^{16}$ prospective screening of remethylation disorders by sole implementation of a low cutoff value for Met without reflexing to the second-tier test could result in significant numbers of false-positive events. However, the common practice to request a repeat specimen or to wait 2 weeks or more for a routine collection of a second sample could delay intervention beyond the narrow window of time that is critical to maximize the likelihood of a favorable outcome. This situation could be partially mitigated by processing the full amino acid profile using a postanalytical tool freely available on the website of the R4S project (http://www.clir-r4s.org). ${ }^{17}$ This tool expands the panel of informative markers by including additional ratios between Met and other routinely measured amino acids, namely isoleucine/leucine, citrulline, and tyrosine. The degree of overlap between reference ranges and disease ranges of these markers is shown in Figure 1; the actual values of the ratios for five patients are summarized in Table 3, together with the scores calculated by the multivariate pattern recognition software utilized in R4S as described previously. ${ }^{18}$ All cases had an informative score, defined as a value either equal to or higher than the score corresponding to the first percentile rank of all available cases $(N=16)$. Furthermore, the R4S tool effectively limits the count of potentially abnormal cases by filtering

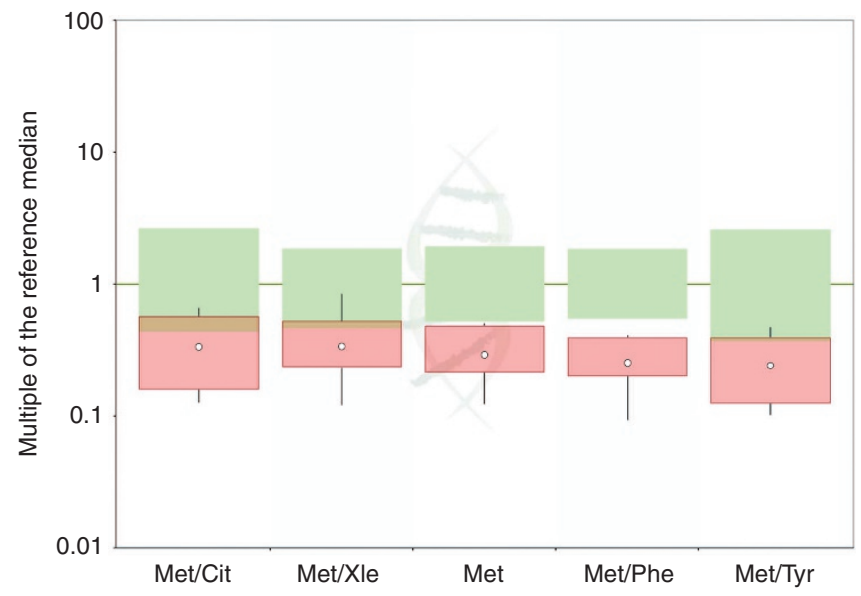

Figure 1 Region 4 Stork plot by condition for remethylation disorders $(\boldsymbol{N}=\mathbf{1 6})$. This plot converts each case value to the corresponding multiple of the reference median. Each box represents the interval between the 10th and 90th percentiles, and the upper and lower lines extend to the 99th and 1st percentiles, respectively. The median is shown as a white circle in the body of the box. Cit, citrulline; Met, methionine; Phe, phenylalanine; Tyr, tyrosine; $\mathrm{Xle}$, isoleucine/leucine. Red, disorder ranges of informative markers; green, 1 st percentile to 99 th percentile range of reference population.

Table 3 Additional ratios utilized for calculation of a score using the Region 4 Stork (R4S) postanalytical tool for remethylation disorders

\begin{tabular}{|c|c|c|c|c|}
\hline \multirow[b]{2}{*}{ Case } & \multicolumn{3}{|c|}{ Amino acid ratios } & \multirow{2}{*}{$\frac{\text { R4S }}{\text { Score }}$} \\
\hline & Met/Xle & Met/Tyr & Met/Cit & \\
\hline 1 & 0.15 & 0.10 & 0.75 & 20 \\
\hline 2 & 0.10 & 0.11 & 0.89 & 4 \\
\hline 3 & 0.06 & 0.05 & 0.31 & 143 \\
\hline 4 & 0.05 & 0.03 & 0.20 & 255 \\
\hline 5 & 0.08 & 0.08 & 0.74 & 13 \\
\hline Reference ranges ${ }^{a}$ & $0.08-0.32$ & $0.10-0.72$ & $0.70-4.20$ & $<4$ \\
\hline
\end{tabular}

Cit, citrulline; Met, methionine; Tyr, tyrosine; Xle, isoleucine/leucine.

aFrom R4S (http://www.clir-r4s.org). 
out instances of cases in which low concentrations of Met are caused by poor nutritional status (i.e., most amino acids are low) and/or analytical artifacts.

\section{RESULTS}

Homocysteine remethylation defects result in functional methionine synthase deficiency. Known defects include deficiencies of cobalamin metabolism ( $c b l E, c b l G$, and $c b l D 1$ complementation groups), as well as severe MTHFR deficiency. In this study we describe four patients with remethylation disorders identified prospectively by NBS within days after birth and compare them with a patient who was diagnosed at 3 months of age when already severely affected. To our knowledge, cases 1 and 2 are the first reported examples of prospectively diagnosed Hcy remethylation disorders through introduction of low cutoff values for Met and Met/Phe ratio followed by second-tier testing for tHcy in the same specimen submitted for NBS.

The clinical presentation of different remethylation disorders share many overlapping features, with the notable exception of hematological findings, not typical for severe MTHFR deficiency. With the increasing number of reported patients, the natural history of these disorders becomes clearer. ${ }^{12,19-21}$ The majority of patients are diagnosed after being symptomatic (with rare exceptions, including siblings of known patients ${ }^{22}$ or populations with high carrier frequency ${ }^{4}$ ). Although the age of onset varies significantly, most of the patients with remethylation disorders present during the first 3 years of life with predominantly neurological manifestations. ${ }^{1,19,21}$ In one series, $92 \%$ of patients with $c b l G$ and $c b l E$ defects had disease onset before 3 years of age, with peak during the first year of life $(75 \%){ }^{21}$ Similar data are reported for cases of severe MTHFR deficiency. ${ }^{19}$ Fatal outcomes, particularly in cases of severe MTHFR deficiencies, are not uncommon. ${ }^{19}$ Remethylation disorders diagnosed later in life have also been described. ${ }^{1,21}$ Many of them have been subjected to long diagnostic work-up for nonspecific predominantly neurologic symptoms until elevation of tHcy was detected. Several patients presenting with isolated hematologic abnormalities, ${ }^{23}$ acute psychosis in adult patients, ${ }^{24}$ or asymptomatic patients ${ }^{12,22}$ have also been reported. Most of the patients responded (at least partially) to specific therapy, with improvement of the severity of the symptoms and of the biochemical markers of the disease. However, the delays in the diagnosis and treatment are recognized as the most important factor leading to residual morbidity in these patients. ${ }^{1,420,21}$ In several cases specific therapy started very early in life or in asymptomatic patients $s^{4,25}$ led to normal outcomes.

The treatment of remethylation disorders is aimed at either bypassing the biochemical block or augmenting the residual activity with cofactors of the affected enzymes. This is achieved by supplementation with Met and/or betaine in addition to vita$\min B_{12}$ and folic acid administration. The therapeutic utility of betaine either alone in cases of severe MTHFR deficiency , $^{1,4,19,20}$ or in combination with vitamin $\mathrm{B}_{12}$ in $c b l G$ and $c b l E$ complementation type disorders ${ }^{1,20,21}$ has been well-established. Betaine increases Met and has Hcy-lowering effects, thus targeting the two predominant mechanisms involved in the pathogenesis of these disorders, defective regeneration of Met with subsequent hypomethioninemia and low $S$-adenosylmethionine levels (resulting in impaired methylation) and hyperhomocystinemia. ${ }^{20,26}$ Because the enzyme involved in the betaine metabolism (betaine-homocysteine methyltransferase, BHMT) is expressed predominantly in the liver and kidneys but not in the brain, ${ }^{27}$ it has been suggested that oral Met supplementation might be a reasonable therapeutic intervention, at least in the neonatal period, for faster restoration of cerebral Met levels, especially when given in combination with betaine. ${ }^{20}$ Pyridoxine was added to the treatment regimen to facilitate lowering the Hcy levels as a cofactor of cystathionine $\beta$-synthase. ${ }^{28}$ Because MTHFR is a flavin adenine dinucleotide-dependent enzyme, riboflavin was also added to the regimen..$^{28}$ The therapeutic goals were guided by the clinical presentation (or lack thereof in asymptomatic patients) and biochemical parameters, including normalization of low Met levels and reduction of Hcy. In cases of MTHFR deficiency, vitamin $B_{12}$ was discontinued; in all cases, betaine dose was adjusted according to patient weight. Normalization of the Met was achieved in all patients and the tHcy remained elevated, although significant reduction was achieved (see Table 1). The same trend has been reported previously in other patients with remethylation disorders. ${ }^{19-21}$

Both patients 1 and 2 were asymptomatic at the time of diagnosis and have continued to reach expected developmental milestones with therapeutic intervention consisting of betaine, hydroxycobalamin, folate, riboflavin, pyridoxine, and aspirin. Cases 3 and 4 were identified by NBS using low Met as marker for remethylation disorders. tHcy was measured as part of a targeted metabolic evaluation at the time of the initial evaluation. Case 3 presented at age 16 days with a severe apneic episode requiring intubation. The treatment of case 4 started earlier, and mechanical ventilation was not initiated despite the breathing problems. Both patients experienced good recovery after specific therapy was initiated, although case 3 has had mild hypotonia and moderate developmental delay after not receiving full treatment. In comparison, case 5 was diagnosed at age 3 months after severe clinical presentation and, despite the good response to treatment, has irreversible neurologic deficits. Although it could be premature to conclude that early therapy altered the patients' clinical outcomes, they have already been followed-up longer than the early-presenting patients described in the literature. ${ }^{1,19,21}$

\section{DISCUSSION}

Overall, our findings confirm the observations that treatment for remethylation disorders should be initiated as soon as possible. ${ }^{2-4,20,29}$ Although treatment strategies for this group of disorders may differ slightly for each specific entity, the same general principles are applicable to the entire group and there is no tangible risk of harm by prescription of a combination treatment of all medications immediately after the finding of elevated tHcy in dried blood spots and a rapid confirmation in plasma, the latter being a routinely available test. 
Evidence of benefits derived from early intervention needs to be balanced by sensitivity and particularly specificity of the screening assay. Low Met has been added as a secondary screening analyte in cases of moderate propionylcarnitine (C3) elevations detected by NBS. ${ }^{30}$ In 2010, Tortorelli et al. ${ }^{5}$ proposed a sequential interpretation algorithm as a strategy for detection of remethylation disorders, and several cases were evaluated by retrospective analysis of newborn blood spots from patients affected by this group of conditions. The now routinely available combination of enhanced postanalytical interpretation and an extremely dependable 2nd tier test (the lowest tHcy concentration in confirmed true positive cases been to date four fold higher than the $99 \%$ ile of the reference population) actually exceeds the prospective screening performance of the most recent addition to the recommended uniform screening panel, severe combined immunodeficiency. ${ }^{31}$ In an accompanying editorial, ${ }^{32}$ utilization of R4S tools was recognized as a potential approach for performance improvement.

In summary, disorders resulting from defective remethylation of tHcy to Met usually present early in life and timely treatment is crucial to prevent significant morbidity and mortality. This report lends support to the argument that remethylation disorders should be considered for inclusion in the recommended uniform screening panel. ${ }^{33,34}$

\section{DISCLOSURE}

The authors declare no conflict of interest.

\section{REFERENCES}

1. Ogier de Baulny H, Gérard M, Saudubray JM, Zittoun J. Remethylation defects: guidelines for clinical diagnosis and treatment. Eur J Pediatr 1998;157(suppl 2):S77-S83.

2. Watkins $D$, Rosenblatt DS. Inborn errors of cobalamin absorption and metabolism. Am J Med Genet C Semin Med Genet 2011;157C:33-44.

3. Rosenblatt DS, Cooper BA, Schmutz SM, Zaleski WA, Casey RE. Prenatal vitamin B12 therapy of a fetus with methylcobalamin deficiency (cobalamin E disease). Lancet 1985;1:1127-1129.

4. Strauss KA, Morton DH, Puffenberger EG, et al. Prevention of brain disease from severe 5,10-methylenetetrahydrofolate reductase deficiency. Mol Genet Metab 2007:91:165-175.

5. Tortorelli S, Turgeon CT, Lim JS, et al. Two-tier approach to the newborn screening of methylenetetrahydrofolate reductase deficiency and other remethylation disorders with tandem mass spectrometry. I Pediatr 2010;157:271-275.

6. Turgeon $C T$, Magera MJ, Cuthbert CD, et al. Determination of total homocysteine, methylmalonic acid, and 2-methylcitric acid in dried blood spots by tandem mass spectrometry. Clin Chem 2010;56:1686-1695.

7. Schuh S, Rosenblatt DS, Cooper BA, et al. Homocystinuria and megaloblastic anemia responsive to vitamin B12 therapy. An inborn error of metabolism due to a defect in cobalamin metabolism. N Engl J Med 1984;310:686-690.

8. Carmel R, Watkins D, Goodman SI, Rosenblatt DS. Hereditary defect of cobalamin metabolism (cblG mutation) presenting as a neurologic disorder in adulthood. N Eng/ J Med 1988;318:1738-1741.

9. Gulati S, Baker P, Li YN, et al. Defects in human methionine synthase in cblG patients. Hum Mol Genet 1996;5:1859-1865.

10. Dixon MM, Huang S, Matthews RG, Ludwig M. The structure of the C-terminal domain of methionine synthase: presenting S-adenosylmethionine for reductive methylation of B12. Structure 1996;4:1263-1275.

11. Schwarz JM, Cooper DN, Schuelke M, Seelow D. MutationTaster2: mutation prediction for the deep-sequencing age. Nat Methods 2014;11:361-362.

12. Zavadáková $P$, Fowler $B$, Suormala $T$, et al. cblE type of homocystinuria due to methionine synthase reductase deficiency: functional correction by minigene expression. Hum Mutat 2005;25:239-247.
13. Wilson A, Leclerc D, Rosenblatt DS, Gravel RA. Molecular basis for methionine synthase reductase deficiency in patients belonging to the cblE complementation group of disorders in folate/cobalamin metabolism. Hum Mol Genet 1999;8:2009-2016.

14. Goyette P, Christensen B, Rosenblatt DS, Rozen R. Severe and mild mutations in cis for the methylenetetrahydrofolate reductase (MTHFR) gene, and description of five novel mutations in MTHFR. Am J Hum Genet 1996;59:1268-1275.

15. Sibani $S$, Leclerc $D$, Weisberg $I S$, et al. Characterization of mutations in severe methylenetetrahydrofolate reductase deficiency reveals an FAD-responsive mutation. Hum Mutat 2003;21:509-520.

16. Hall PL, Marquardt G, McHugh DM, et al. Postanalytical tools improve performance of newborn screening by tandem mass spectrometry. Genet Med 2014;16:889-895.

17. McHugh D, Cameron CA, Abdenur JE, et al. Clinical validation of cutoff target ranges in newborn screening of metabolic disorders by tandem mass spectrometry: a worldwide collaborative project. Genet Med 2011;13:230-254.

18. Marquardt G, Currier R, McHugh DM, et al. Enhanced interpretation of newborn screening results without analyte cutoff values. Genet Med 2012;14:648-655.

19. Diekman EF, de Koning TJ, Verhoeven-Duif NM, Rovers MM, van Hasselt PM Survival and psychomotor development with early betaine treatment in patients with severe methylenetetrahydrofolate reductase deficiency. JAMA Neurol 2014;71:188-194.

20. Schiff M, Benoist JF, Tilea B, Royer N, Giraudier S, Ogier de Baulny H. Isolated remethylation disorders: do our treatments benefit patients? J Inherit Metab Dis 2011:34:137-145.

21. Huemer $M, B u ̈ r e r ~ C$, Ješina $P$, et al. Clinical onset and course, response to treatment and outcome in 24 patients with the cblE or cblG remethylation defect complemented by genetic and in vitro enzyme study data. J Inherit Metab Dis; e-pub ahead of print 20 December 2014.

22. Visy JM, Le Coz P, Chadefaux B, et al. Homocystinuria due to 5,10-methylenetetrahydrofolate reductase deficiency revealed by stroke in adult siblings. Neurology 1991;41:1313-1315.

23. Vilaseca MA, Vilarinho L, Zavadakova P, et al. CblE type of homocystinuria: mild clinical phenotype in two patients homozygous for a novel mutation in the MTRR gene. J Inherit Metab Dis 2003;26:361-369.

24. Michot JM, Sedel F, Giraudier S, Smiejan JM, Papo T. Psychosis, paraplegia and coma revealing methylenetetrahydrofolate reductase deficiency in a 56-year-old woman. J Neurol Neurosurg Psychiatry 2008;79:963-964.

25. Kandula T, Peters H, Fahey M. Cobalamin E defect, a rare inborn error of vitamin B12 metabolism: value of early diagnosis and treatment. J Clin Neurosci 2014;21:1815-1817.

26. Surtees R, Clelland J, Hann I. Demyelination and single-carbon transfer pathway metabolites during the treatment of acute lymphoblastic leukemia: CSF studies. J Clin Oncol 1998;16:1505-1511.

27. Delgado-Reyes CV, Wallig MA, Garrow TA. Immunohistochemical detection of betaine-homocysteine S-methyltransferase in human, pig, and rat liver and kidney. Arch Biochem Biophys 2001;393:184-186.

28. Watkins $D$, Rosenblatt $D S$. Inherited disorders of folate and cobalamin transport and metabolism. In: Valle D, Beaudet AL, Vogelstein B, et al (eds). OMMBID. McGraw-Hill: New York, 2014. http://ommbid.mhmedical.com/content.aspx? bookid=971\&Sectionid=62646147. Accessed 9 February 2015.

29. Forges T, Chery C, Audonnet S, Feillet F, Gueant JL. Life-threatening methylenetetrahydrofolate reductase (MTHFR) deficiency with extremely early onset: characterization of two novel mutations in compound heterozygous patients. Mol Genet Metab 2010;100:143-148.

30. Weisfeld-Adams JD, Morrissey MA, Kirmse BM, et al. Newborn screening and early biochemical follow-up in combined methylmalonic aciduria and homocystinuria, cblC type, and utility of methionine as a secondary screening analyte. Mol Genet Metab 2010;99:116-123.

31. Kwan A, Abraham RS, Currier R, et al. Newborn screening for severe combined immunodeficiency in 11 screening programs in the United States. JAMA 2014;312:729-738.

32. Holtzman NA. Newborn screening for severe combined immunodeficiency: progress and challenges. JAMA 2014;312:701-702.

33. Kemper AR, Green NS, Calonge N, et al. Decision-making process for conditions nominated to the recommended uniform screening panel: statement of the US Department of Health and Human Services Secretary's Advisory Committee on Heritable Disorders in Newborns and Children. Genet Med 2014;16:183-187.

34. Watson MS, Mann MY, Lloyd-Puryear MA, Rinaldo P, Howell RR. Newborn screening: toward a uniform screening panel and system. Executive summary. Genet Med 2006;8:1S-11S. 